Article

\title{
Investigation of the Thickness Differential on the Formability of Aluminum Tailor Welded Blanks
}

\author{
Jie $_{\mathrm{Wu}}{ }^{1, *}$, Yuri Hovanski ${ }^{2} \mathbb{D}$ and Michael Miles ${ }^{2}$ \\ 1 Department of Mechanical Engineering, Hunan Institute of Technology, Hengyang 421002, China \\ 2 Department of Manufacturing Engineering, Brigham Young University, Provo, UT 84602, USA; \\ yuri.hovanski@byu.edu (Y.H.); mmiles@byu.edu (M.M.) \\ * Correspondence: 2012001757@hnit.edu.cn; Tel.: +86-182-2928-5927
}

check for

updates

Citation: Wu, J.; Hovanski, Y.; Miles, M. Investigation of the Thickness Differential on the Formability of Aluminum Tailor Welded Blanks. Metals 2021, 11, 875. https://doi.org/ $10.3390 /$ met11060875

Academic Editor: Christof Sommitsch

Received: 10 April 2021

Accepted: 25 May 2021

Published: 27 May 2021

Publisher's Note: MDPI stays neutral with regard to jurisdictional claims in published maps and institutional affiliations.

Copyright: (c) 2021 by the authors. Licensee MDPI, Basel, Switzerland. This article is an open access article distributed under the terms and conditions of the Creative Commons Attribution (CC BY) license (https:// creativecommons.org/licenses/by/ $4.0 /)$.

\begin{abstract}
A finite element model is proposed to investigate the effect of thickness differential on Limiting Dome Height (LDH) testing of aluminum tailor-welded blanks. The numerical model is validated via comparison of the equivalent plastic strain and displacement distribution between the simulation results and the experimental data. The normalized equivalent plastic strain and normalized LDH values are proposed as a means of quantifying the influence of thickness differential for a variety of different ratios. Increasing thickness differential was found to decrease the normalized equivalent plastic strain and normalized LDH values, this providing an evaluation of blank formability.
\end{abstract}

Keywords: thickness differential; limiting dome height; tailor welded blank

\section{Introduction}

The use of tailor welded blanks (TWBs) has enabled automotive manufacturers to optimize material use in sheet metal assembly by selectively varying material thickness, alloy and/or temper type and surface coatings [1]. Over the past few decades, steel TWBs have rapidly developed into numerous commercial products, due to the weight and cost reduction over traditional monolithic stampings. However, the continuous drive to further decrease the weight of vehicles, to improve efficiency, and reduce greenhouse gas emissions, has led to integration of more light metal components into the autobody structure. However, there are several difficulties that must be confronted when producing TWBs from aluminum alloy sheets. Aluminum alloys typically have much lower levels of room temperature formability than steel, while the weldability of aluminum is also more challenging when considering high volume fabrication of tailored blanks. As a solid state welding process, friction stir welding (FSW) is considered as a promising joining technique providing one of the best alternatives to fusion welding (such as laser welding) in order to produce a good combination of microstructure, mechanical properties and formability [2-4]. Friction stir welding may be used for various geometries including lap welding, T-joints, and butt welding. Additionally, as a solid-state welding process it can be a grain refinement technique for different materials such as aluminum, magnesium, copper, and steels [5-7]. FSW has been demonstrated as an enabling technology for production of aluminum TWBs $[1,8,9]$. However, there are numerous challenges that remain to be overcome, leading to the need for better analysis tools for studying the effect of blank design on formability performance [7]. The limiting dome height (LDH) test [10-12] is often used to assess the formability of tailor-welded blanks experimentally, and these results have been employed to validate models for simulating the effect of blank design on LDH performance.

According to other published literature, the factors influencing the formability of TWBs are the thickness ratio of the base materials [13,14], strength ratio of base materials [15], and other factors such as weld geometry and mismatch of material between weld 
zone and base materials [16]. Panda et al. [12] investigated the formability of three different TWBs in biaxial tension, where LDH tests were used to evaluate post-weld formability. The effect of blank thickness ratio was studied and the results showed that LDH decreases as the thickness ratio increases. Leitão et al. [16] documented the influence of the type of mismatch in mechanical properties between weld and base materials on formability of aluminum TWBs. However, the same thickness ratio can be obtained by different combination of base materials. Thus, the limiting thickness ratio (LTR) was introduced as a new factor for prediction of forming limits in TWBs [11].

The most reliable method to investigate the influences of thickness differentials in TWBs on their formability is experimental. However, it is costly to obtain these results over a varying range of thickness differentials that could be explored for design purposes. Therefore, the current study proposes a finite element simulation approach to investigate the formability of tailor welded blanks. Prior work in this area has yielded some useful results. For example, Chien et al. [17] employed finite element modeling to estimate the onset of failure in transversely loaded AA5754 TWBs, where the predicted results by simulation compared well with the experimental data. The influences of thickness ratio of base sheets on formability of tailor welded blanks were examined based on three-dimensional finite element models. The failure onset sites of tailor welded blanks were predicted and the quantitative relationships between the Erichsen index values and base thickness ratio were established using the finite element software ABAQUS (Dassault Simulia, version 6.10, Paris, France) [18]. Wang et al. [19] studied the deformation characteristics of AA6082 tailor-welded blanks of different thickness combinations by a finite element model during the hot stamping process. Good agreements were achieved between the predicted and experimental results, from which studies were extended to predict the forming features of $1.5 \mathrm{~mm}$ to $2.0 \mathrm{~mm}$ TWBs.

As previous studies have focused on evaluating formability with varying thickness ratios as a means of establish a LTR, this study was designed to investigate how formability of TWBs is affected by changes in thickness differential with a fixed thickness ratio. An understanding of how formability limits may change for a fixed thickness ratio is critical to further enabling rapid industrial implementation of aluminum TWBs. In this paper, results from a finite element model that was developed and validated by experimental results is presented. Building on the prior work, some new insights have been gained regarding the formability of aluminum TWBs for fixed thickness ratios and increasing thickness differentials between dissimilar thickness welded blanks, using the finite element software ForgeNxT (version 2.1, Transvelor, Sophia Antipolis, France) [20].

\section{Experiments and Numerical Modeling}

The commercial FEA software package ForgeNxT was utilized to model the limiting dome height deformation process. Figure 1 shows the FE simulation set-up for the LDH tooling. The model consists of 4 parts: punch, blank, upper clamp, and lower clamp.

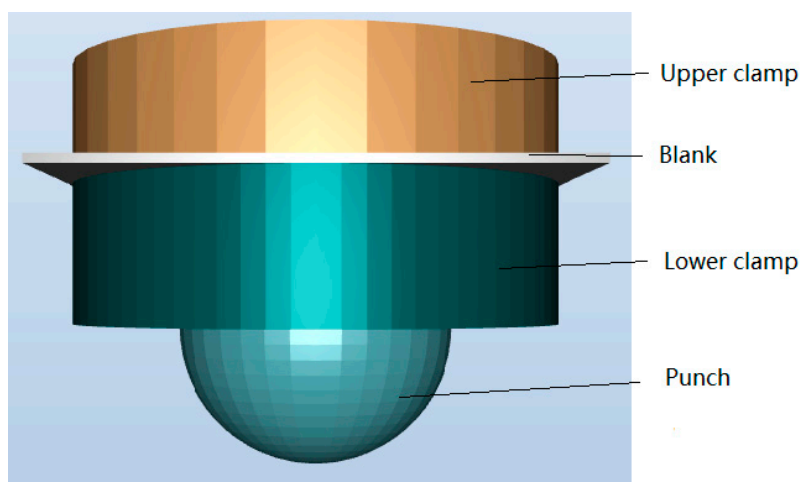

Figure 1. The set-up of finite element model of ForgeNxT software. 
A model of the forming process was developed using a finite element approach within the Forge Nxt [20] software package. An updated Lagrangian scheme with explicit time integration was employed to model the flow of the sheet material, subjected to boundary conditions of restraint around the edges of the blank and velocity boundary conditions imposed by a rigid tool. Material flow was calculated from a three dimensional velocity field. Heat generated by friction and the deformation of the material was also taken into account. An isotropic, viscoplastic Norton-Hoff law was used to model the evolution of material flow stress as a function of strain, strain rate, and temperature. The expression for the deviatoric stress tensor is shown below:

$$
\mathrm{s}=2 K(\sqrt{3} \dot{\bar{\varepsilon}})^{m-1} \dot{\varepsilon}
$$

where $\dot{\varepsilon}$ is the strain rate tensor, $\dot{\bar{\varepsilon}}$ is the effective strain rate, $K$ is the material consistency, and $m$ is the strain rate sensitivity. The material consistency $K$ is a function of temperature $\mathrm{T}$ and equivalent strain $\dot{\bar{\varepsilon}}$, where $\mathrm{n}$ is the strain hardening exponent and $\beta$ is a thermal softening parameter:

$$
K=K_{0}\left(\varepsilon_{0}+\bar{\varepsilon}\right)^{n} e^{\frac{\beta}{T}}
$$

This viscoplastic law is capable of modeling material flow stresses in the region of the weld, while also providing the contact stresses with the tool that were used to calculate the friction shear stress at the tool/sheet interface.

Friction at the sliding interface between the sheet and the tool were modeled using a Coulomb law.

$$
\tau=\mu \sigma_{n}
$$

where $\mu$ is the friction coefficient, $\sigma_{\mathrm{o}}$ is the current yield stress of the sheet material, and $\sigma_{n}$ is the normal stress at the contact surface.

Calculation of the flow of material was based on a finite element discretization using an enhanced 3-noded triangular element, where equilibrium equations were solved at each increment using the Newton-Raphson method. The unilateral contact condition was applied to the sheet surfaces by means of a nodal penalty formulation, where both the tool and clamping dies were considered rigid.

For the finite element modeling, the most important aspect is to validate the numerical model proposed here for prediction of the LDH value by comparing the computed results with experimental data. This requires a comparison of the numerical results in terms of equivalent plastic strain and displacement distribution with the results obtained in the experimental. The aluminum alloy AA 5754-O was used in both experimental and simulation validation. AA 5754 has been an alloy of choice for the automotive structural application owing to its excellent ductility and formability characteristics. The chemical composition and relevant mechanical properties of AA5754 are shown in Tables 1 and 2. For numerical validation, the LDH deformation process is simulated in base material AA5754, with blank thickness of $3 \mathrm{~mm}$, without a weld seam.

Table 1. Chemical composition of AA5754.

\begin{tabular}{rcccc}
\hline Al & Si & Mn & Mg & Fe \\
\hline Bal. & 0.4 & 0.5 & $2.6-3.2$ & 0.4 \\
\hline
\end{tabular}

Table 2. Mechanical properties of AA5754.

\begin{tabular}{cccc}
\hline Tensile Strength, MPa & Yield Strength, MPa & Elongation, \% & Vickers Hardness \\
\hline 215 & 140 & 25 & 67.2 \\
\hline
\end{tabular}

The goal of the study is to investigate the effects of thickness differential on the limiting dome height value in aluminum tailor welded blanks. Thickness ratios of $1.5: 1$ and 2:1, with 
varying thickness differentials are considered in our simulation work. For the thickness ratio 1.5:1, four thickness differentials are investigated: $0.5 \mathrm{~mm}(1.5 \mathrm{~mm}: 1 \mathrm{~mm}), 0.75 \mathrm{~mm}$ $(2.25 \mathrm{~mm}: 1.5 \mathrm{~mm}), 1 \mathrm{~mm}(3 \mathrm{~mm}: 2 \mathrm{~mm})$, and $1.25 \mathrm{~mm}(3.75 \mathrm{~mm}: 2.5 \mathrm{~mm})$, respectively. For thickness ratio 2:1, three thickness differentials are investigated: $1 \mathrm{~mm}(1 \mathrm{~mm}: 2 \mathrm{~mm})$, $1.5 \mathrm{~mm}(1.5 \mathrm{~mm}: 3 \mathrm{~mm})$, and $2 \mathrm{~mm}(2 \mathrm{~mm}: 4 \mathrm{~mm})$, respectively.

In the present work, limiting dome height tests were carried out to validate the numerical prediction of $\mathrm{LDH}$ values of the blanks and also to check the equivalent plastic strain distribution obtained in the simulations. An Interlaken Servo Press 75 system (Interlaken Technology Corporation, Chaska, MN, USA), shown in Figure 2a was used for conducting the LDH tests. The sample is rigidly clamped with a grooved clamp-down ring and stretched to fracture with a $100 \mathrm{~mm}$ diameter hemispherical dome. The maximum load at fracture is measured and the height of the dome at peak load can be used to define the limit of formability, since plastic instability occurs beyond this point. The ARAMIS Digital Image Correlation (DIC) system (GOM, Braunschweig, Germany) shown in Figure 2b, is used for measuring and visualizing both displacement distribution and equivalent plastic strain.

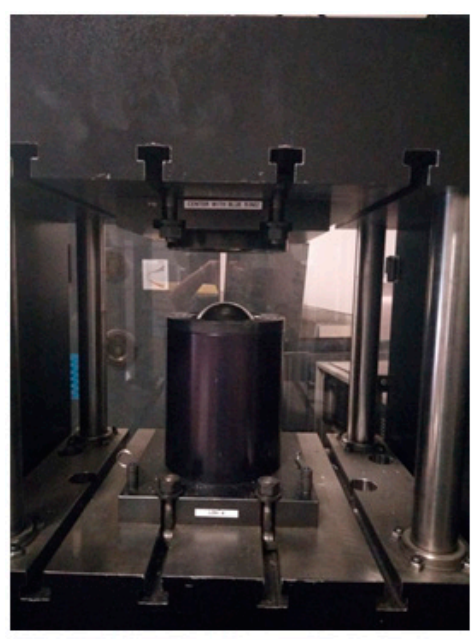

(a)

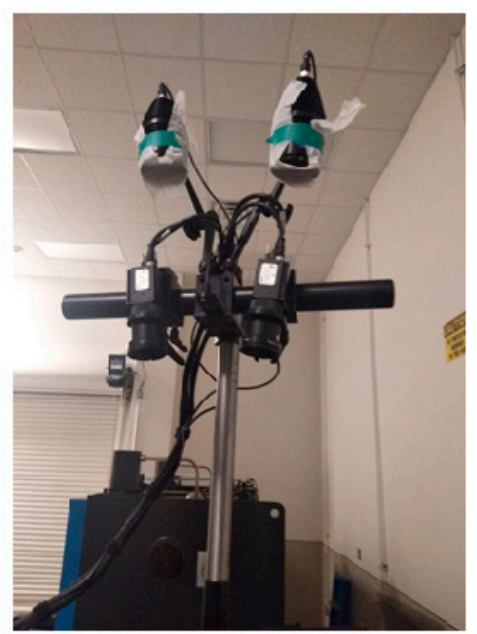

(b)

Figure 2. (a) Experimental set-up of LDH (Limiting Dome Height) test and (b) ARAMIS DIC (Digital Image Correlation) test system.

\section{Results and Discussion}

\subsection{Comparison Between the Simulation and Experiment Results}

In order to validate the accuracy of the simulation model, the equivalent plastic strain and displacement distribution were compared at two different punch displacements before the occurrence of fracture in the blank. A cross section of the deformed blanks (as shown in Figure 3 as displacement $Z$ ) was defined to obtain the equivalent plastic strain and displacement distribution both in experimental and simulated tests. As can be seen from Figure 3, the strain distribution on LDH samples (before fracture) have two peaks symmetrically along the cross section. The same strain distribution is also obtained in steel tailor welded blanks although the variables are major strain and minor strain [12]. A good match was achieved between the experimental and simulated results when the punch displacement is $20 \mathrm{~mm}$. The displacement distribution along the section length could be seen as the deformation profile of the blank while the equivalent plastic strain along the section length could be seen as the equivalent plastic strain distribution along the cross section of the deformation profile in the blank. The result is also true when the punch displacement is $30 \mathrm{~mm}$, as shown in Figure 4. The peak value of equivalent plastic strain is 0.38 , larger than that when punch displacement is $20 \mathrm{~mm}$. The equivalent plastic strain at these two punch displacements can be seen as the lower limit fracture criterion and the upper limit fracture criterion, respectively. 


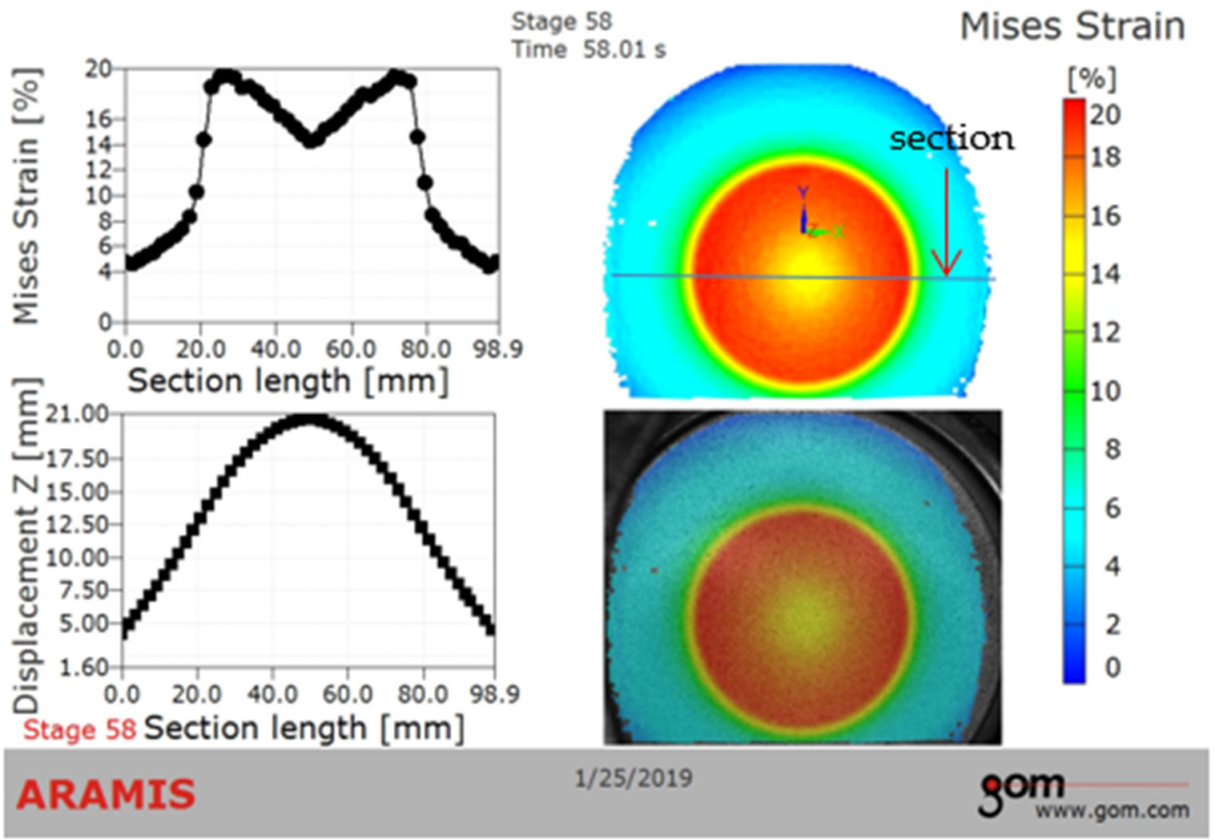

(a)

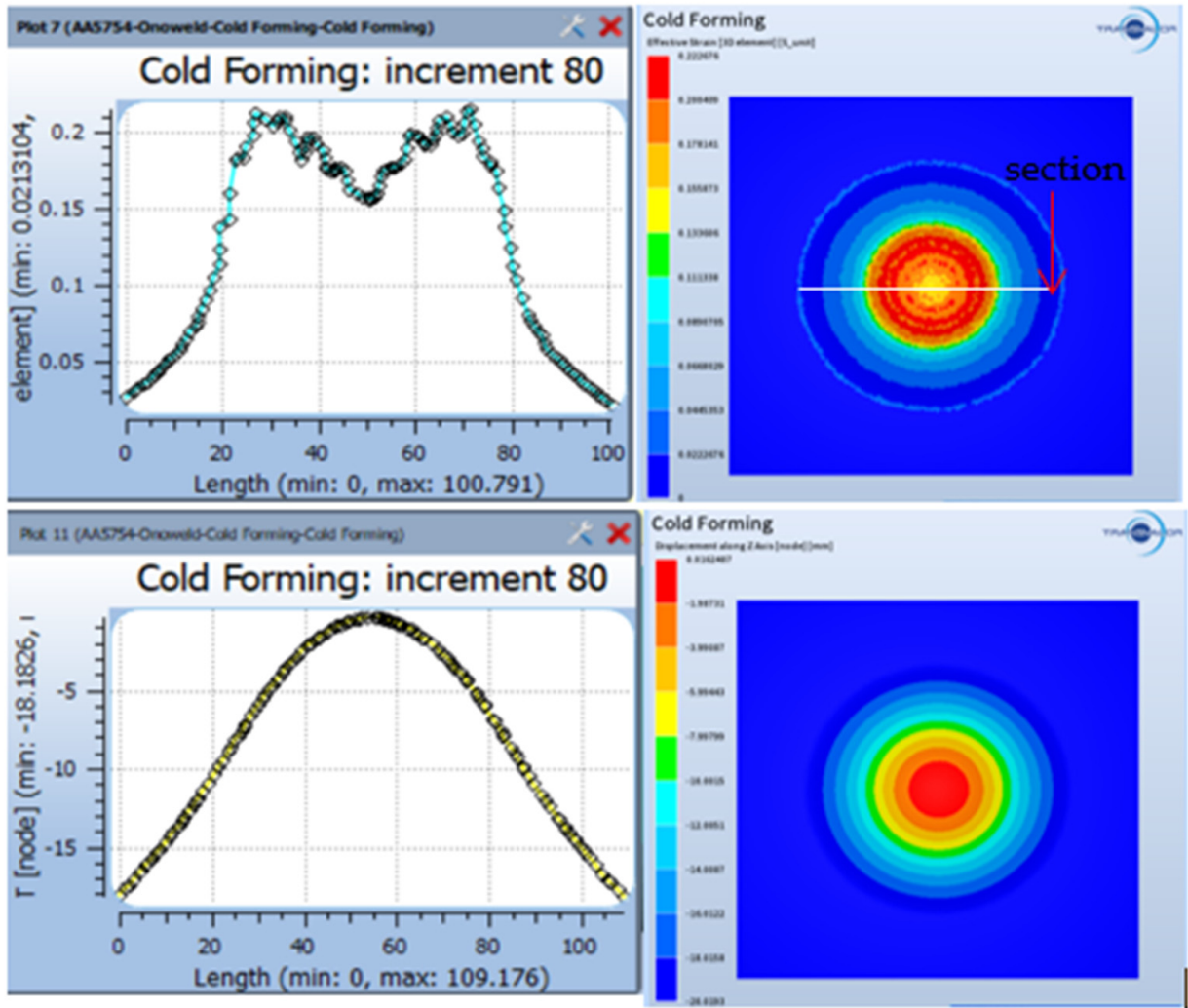

(b)

Figure 3. Comparison of Mises strain and displacement across the blank when punch displacement is $20 \mathrm{~mm}$ between (a) experimental; (b) simulation by ForgeNxT 2.1.

Based on the results for maximum deformation before fracture presented in Figure 3, and industrial strain limits set to prevent material thinning in room-temperature stamping of aluminum TWBs, three equivalent plastic strains were investigated that are representative a different fracture levels that may be sustained in the AA5754. This equivalent plastic strain limits are $18 \%, 22.5 \%$ and $34 \%$, respectively. 


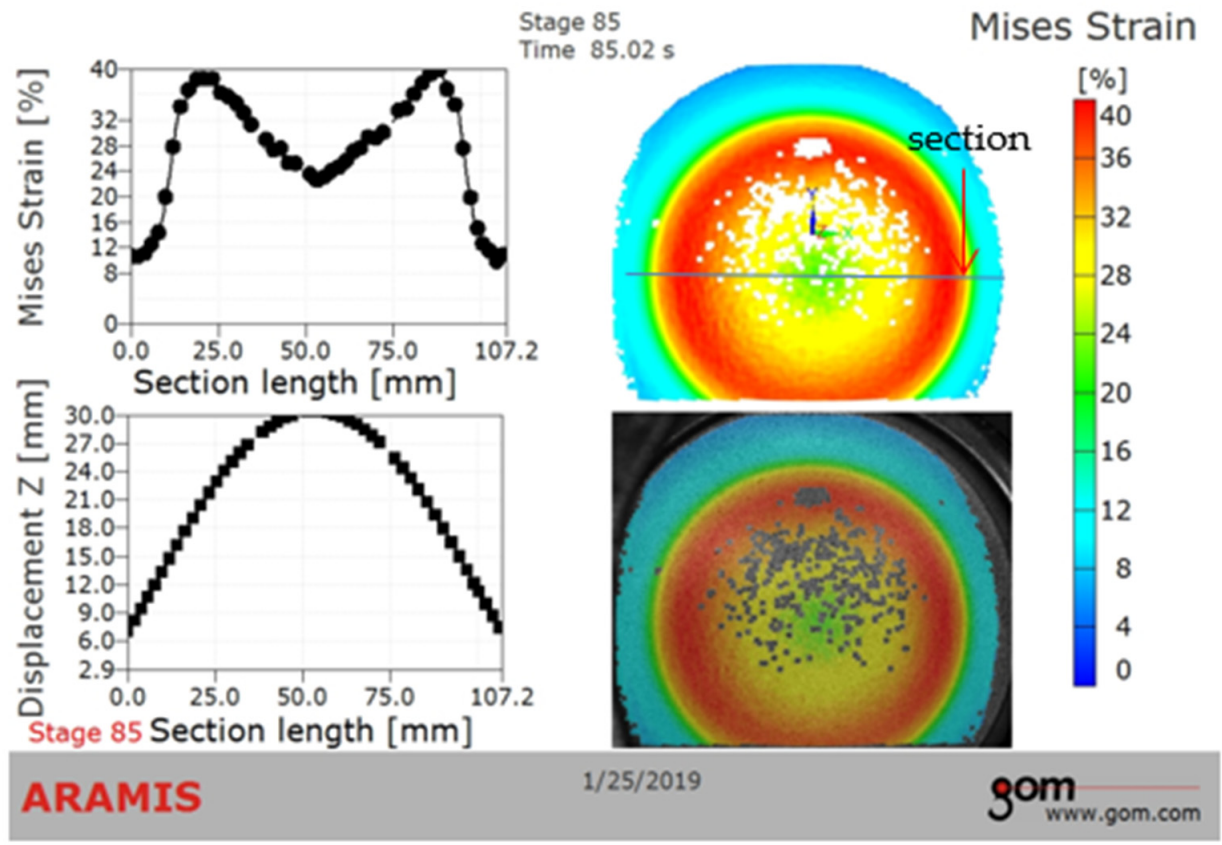

(a)
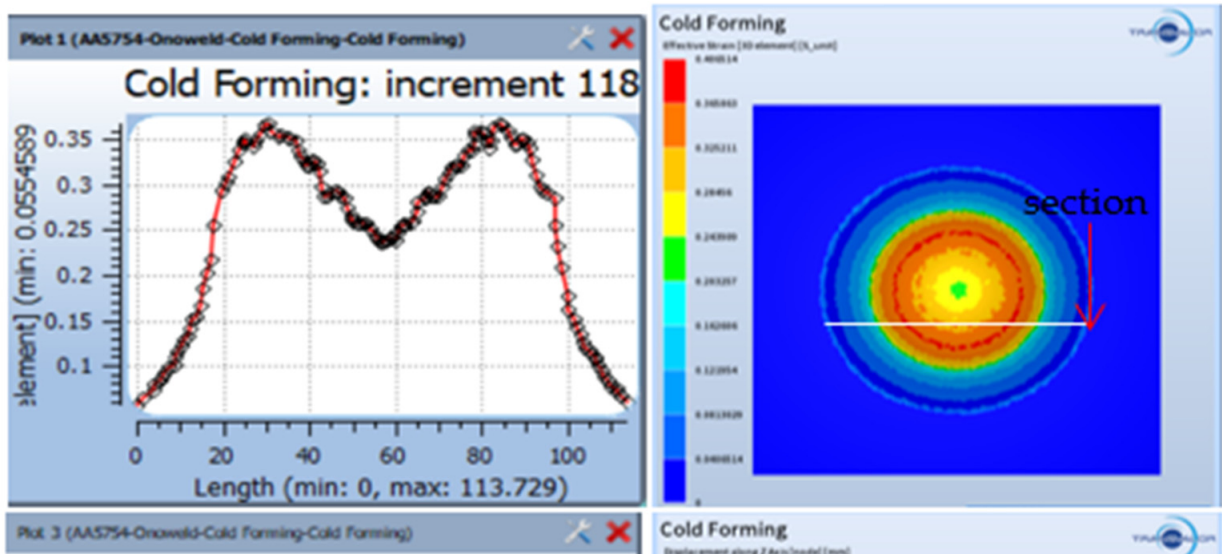

Cold Forming: increment 118
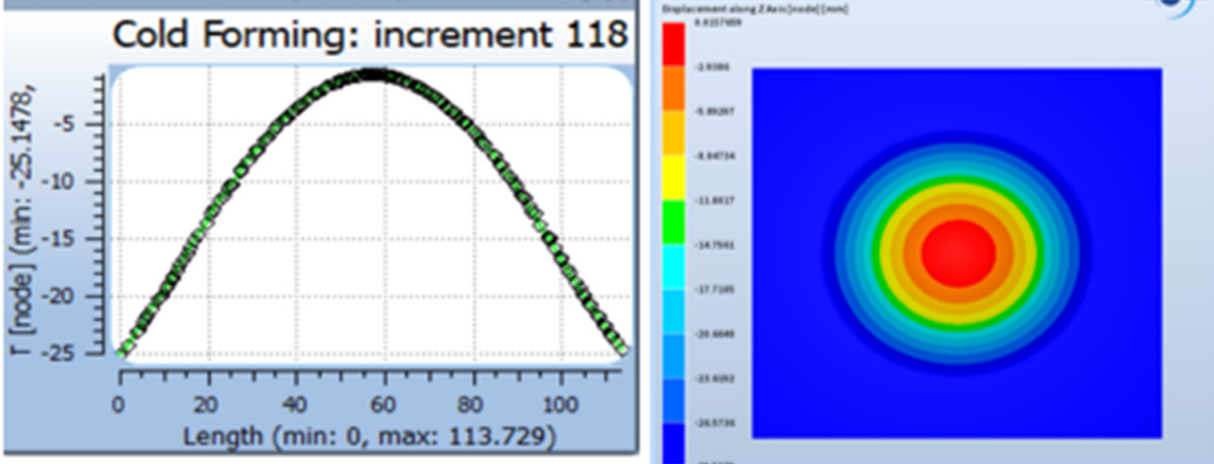

(b)

Figure 4. Comparison of Mises strain and displacement across the blank when punch displacement is $30 \mathrm{~mm}$ between (a) experimental; (b) simulation by Forge NxT.

\subsection{Effect of Thickness Differential on the LDH of Aluminum Tailor Welded Blanks}

As one of the goals of this study is to investigate the effects of increasing the thickness differential on the formability of aluminum TWBs, limiting dome height values of aluminum tailor welded blanks across two specific thickness ratios (TR), 1:1.5 and 1:2, are shown for increasing thickness differentials in Tables 3 and 4 . The data presented in these tables was obtained from simulations. 
Three equivalent plastic strains were investigated; they are $18 \%, 22.5 \%$, and $34 \%$, respectively. The LDH values decrease with increasing thickness differential at the fracture criterion of $18 \%$ and $22.5 \%$. This is true regardless of the thickness ratio, whether it is $1.5: 1$ or $2: 1$. While the LDH values increase with the increasing of the thickness differential for a fracture criterion of $34 \%$. These can be seen clearly in Figure 5 in which the relationship between the LDH values and thickness differentials are shown for fixed thickness ratios. It also can be concluded that the equivalent plastic strain accumulated rapidly for larger thickness differentials, which is the reason the LDH values increase with the increasing thickness differential for the fracture criterion of $34 \%$. These can be seen in Figure 6 , in which, is the equivalent plastic strain distribution in the blank is displayed at different thickness ratios.

Table 3. Simulation results when thickness ratio fixed as 1:1.5. TR: Thickness Ratios. LDH: Limiting Dome Height.

\begin{tabular}{|c|c|c|c|c|c|}
\hline TR & $\begin{array}{c}\text { Thickness } \\
\text { Differential }\end{array}$ & $\begin{array}{c}\text { Strain } \\
\text { at } \\
\text { Displacement } \\
20 \mathrm{~mm}\end{array}$ & $\begin{array}{l}\text { LDH at } \\
\text { Fracture } \\
\text { Strain } \\
18 \%\end{array}$ & $\begin{array}{l}\text { LDH at } \\
\text { Fracture } \\
\text { Strain } \\
22.5 \%\end{array}$ & $\begin{array}{c}\text { LDH at } \\
\text { Fracture } \\
\text { Strain } \\
34 \%\end{array}$ \\
\hline 1:1.5 & 0.5 & 0.217 & 16.38 & 20.29 & 23.08 \\
\hline $1.5: 2.25$ & 0.75 & 0.219 & 16.32 & 20.27 & 23.27 \\
\hline $2: 3$ & 1.0 & 0.224 & 15.39 & 20.04 & 24.18 \\
\hline $2.5: 3.75$ & 1.25 & 0.243 & 14.81 & 18.00 & 23.88 \\
\hline
\end{tabular}

Table 4. Simulation results when thickness ratio fixed as 1:2.

\begin{tabular}{cccccc}
\hline TR & & Strain & LDH at & LDH at & LDH at \\
& $\begin{array}{c}\text { Thickness } \\
\text { Differential }\end{array}$ & $\begin{array}{c}\text { at } \\
\text { Displacement } \\
\text { 20mm }\end{array}$ & $\begin{array}{c}\text { Fracture } \\
\text { Strain } \\
\mathbf{1 8 \%}\end{array}$ & $\begin{array}{c}\text { Fracture } \\
\text { Strain }\end{array}$ & $\begin{array}{c}\text { Fracture } \\
\text { Strain } \\
\mathbf{2 2 . 5 \%}\end{array}$ \\
\hline $1.0: 2.0$ & 1 & 0.225 & 16.15 & 20.00 & 22.50 \\
$1.5: 3.0$ & 1.5 & 0.228 & 15.52 & 19.57 & 24.12 \\
$2.0: 4.0$ & 2 & 0.244 & 15.00 & 18.60 & 24.39 \\
\hline
\end{tabular}

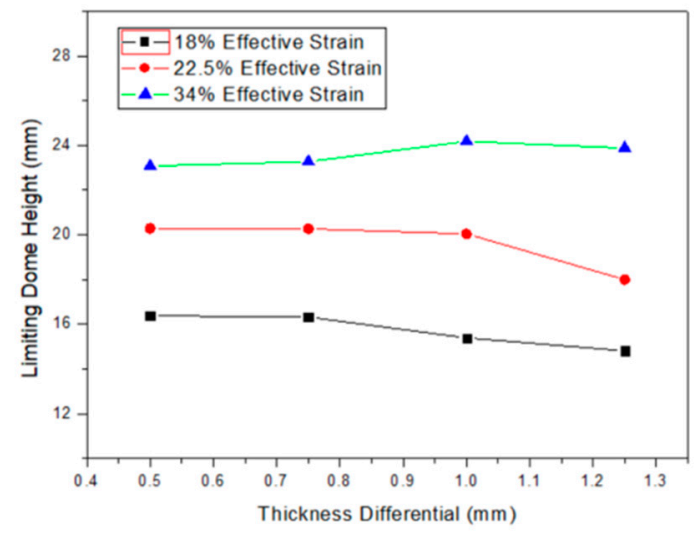

(a)

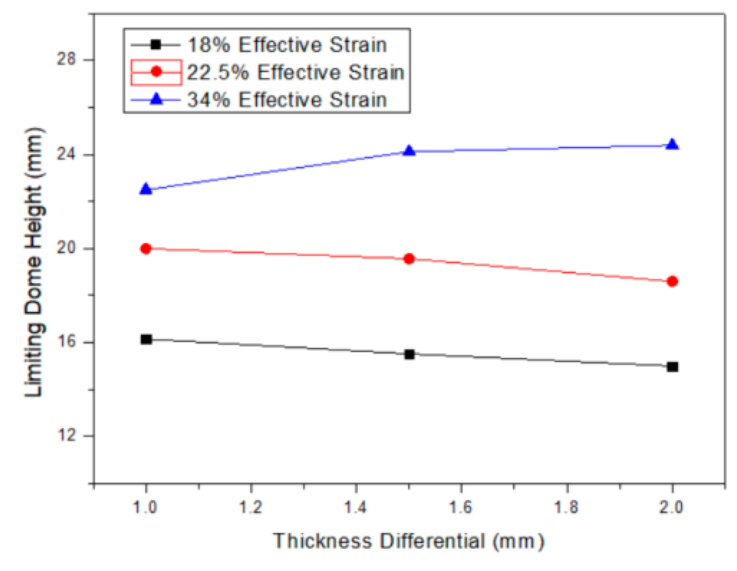

(b)

Figure 5. Limiting Dome Height VS Thickness Differential with fixed thickness ratio (a) TR = 1.5; $(\mathbf{b}) \mathrm{TR}=2$.

In order to clearly describe the influence of thickness differential on the LDH and effective strain, a normalized effective strain and normalized LDH value were proposed, which is defined as the effective strain and LDH divided by the thickness differential. Thus, 
it can be concluded that both the normalized equivalent plastic strain and LDH values are decrease with the increasing of thickness differential, which is shown in Figure 7.

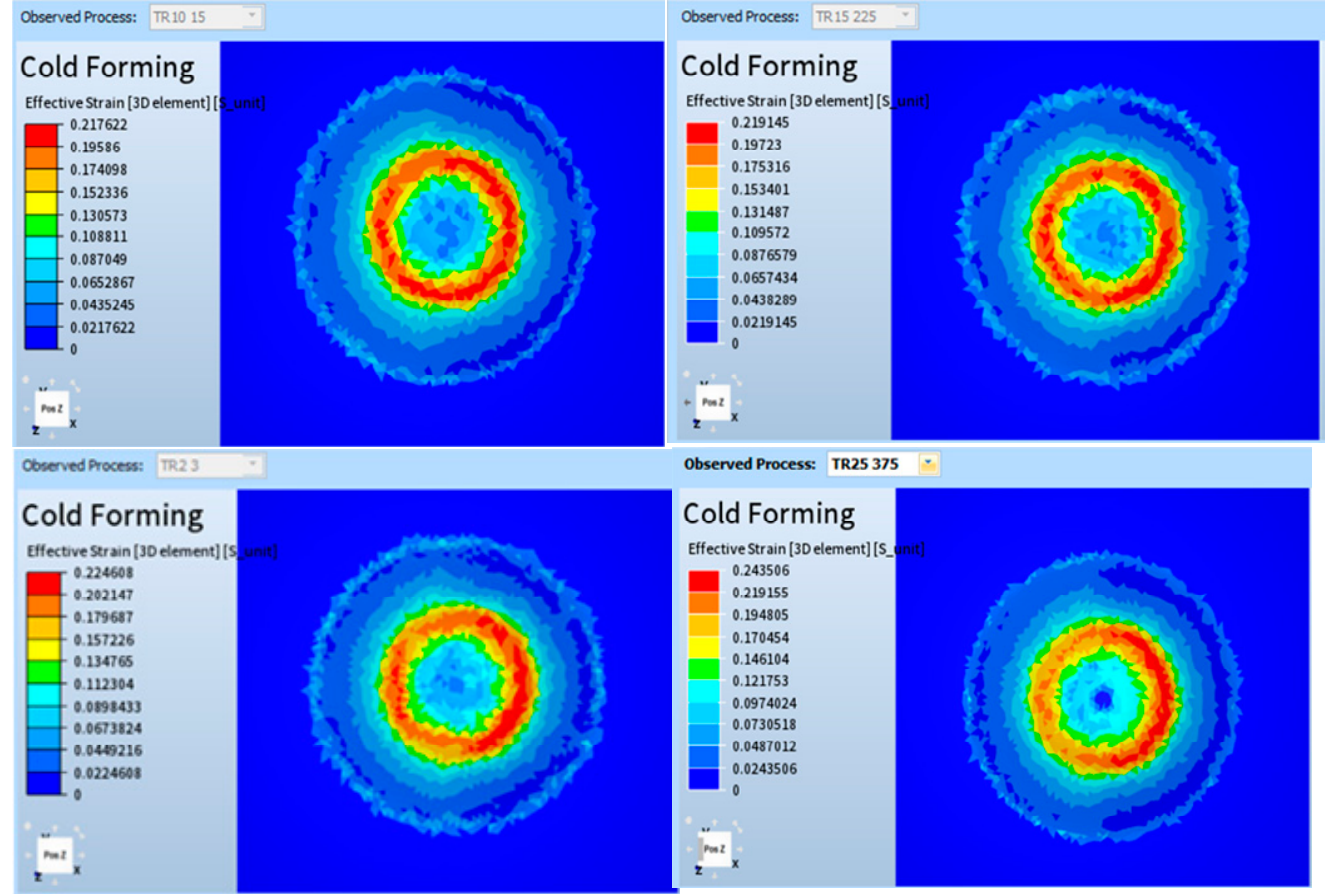

(a)

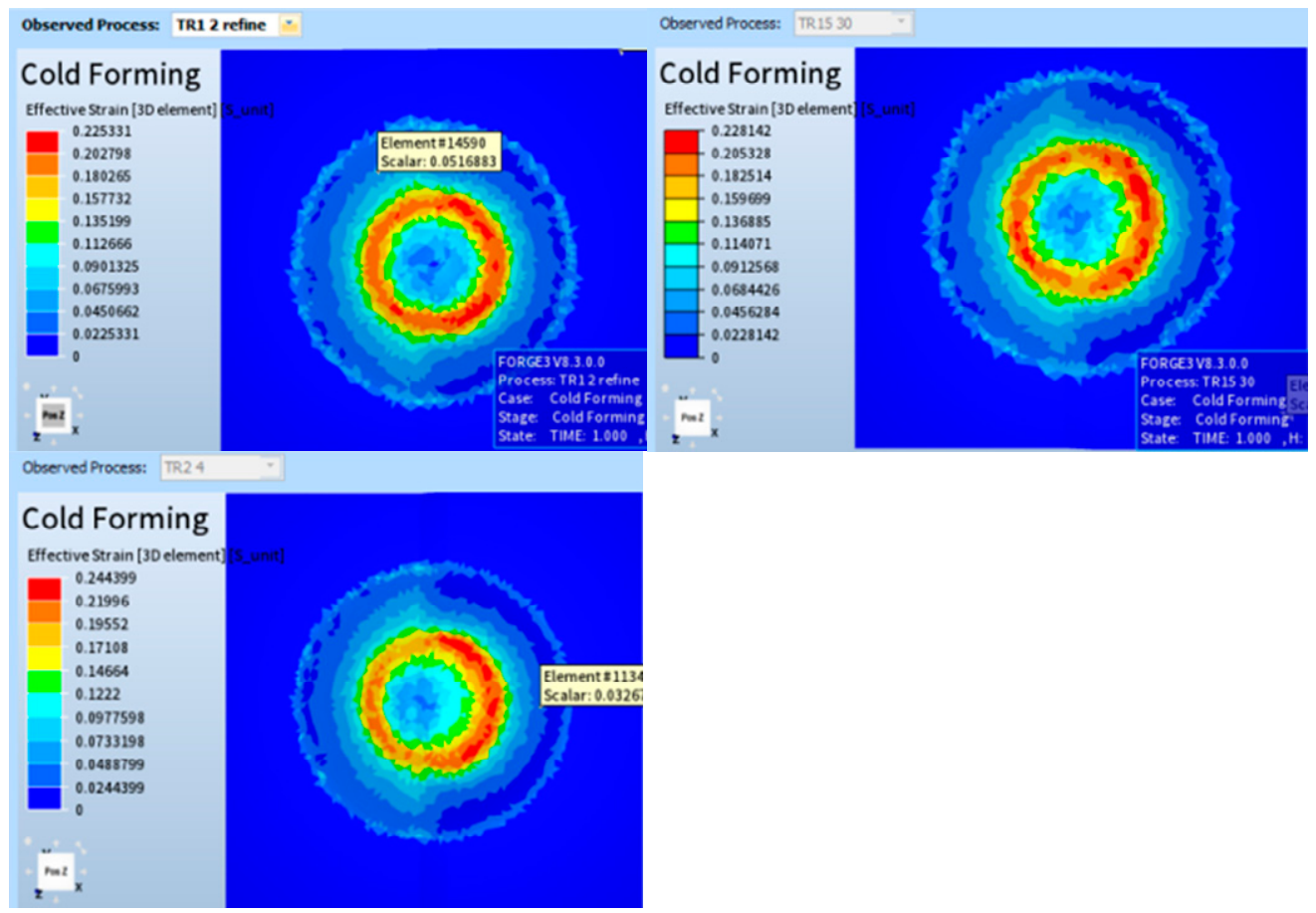

(b)

Figure 6. Equivalent plastic strain distribution in the simulations with different thickness ratio: (a) thickness Ratio is $1.5: 1$; (b) thickness Ratio is 2:1. 


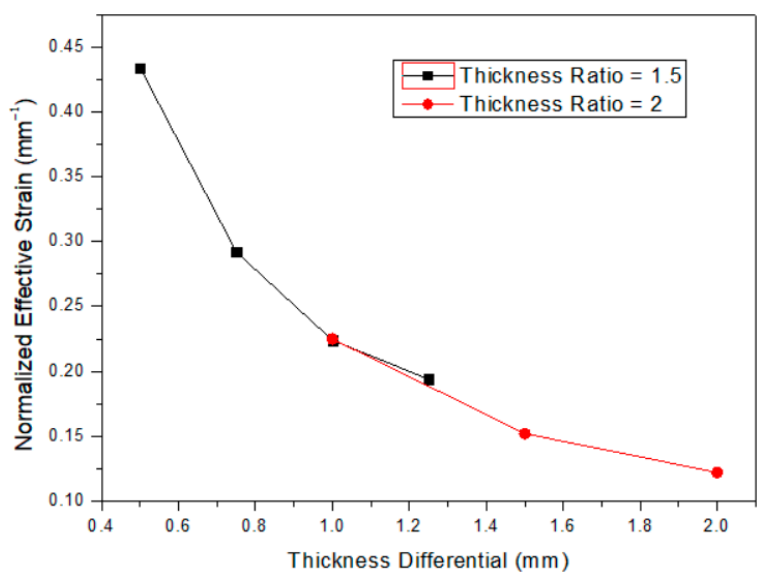

(a)

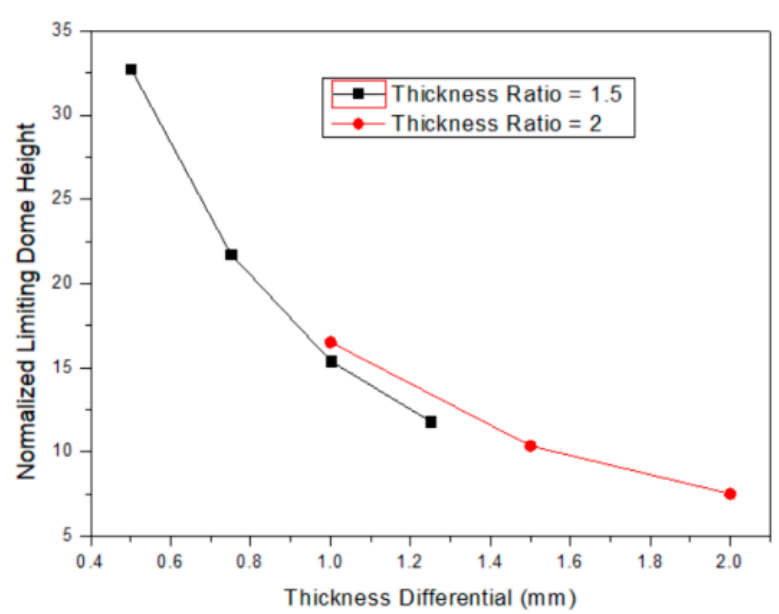

(b)

Figure 7. (a) Relationship between the thickness differential and normalized equivalent plastic strain; (b) relationship between the thickness differential and limiting dome height.

\section{Conclusions}

A ForgeNxt based finite element model was proposed to investigate the effect of varying thickness differentials for several fixed thickness ratios on the LDH value of dissimilar thickness aluminum tailor welded blanks. The numerical model was verified via the comparison of the equivalent plastic strain and displacement distribution between the simulation results and the experimental data.

The results from this study showed that increasing the thickness differential for dissimilar thickness blanks, even while maintaining the same thickness ratio, influenced the predicted behavior differently based on the limiting equivalent plastic strain criteria selected. For instance, when the limiting criterion was set to the ultimate equivalent plastic strain (34\%) found in experimental results, the predicted LDH results showed between a 5 and $10 \%$ increase in predicted $\mathrm{LDH}$ as a given thickness differential increased from 0.5 to 1.25 or 1.0 to $2.0 \mathrm{~mm}$ respectively. Conversely, when the limiting criterion was set based on industrial limits of $18.5 \%$ or $22.5 \%$ equivalent plastic strain designed on industrial thinning limitations of room-temperature stamping, the predicted LDH values actually decreased when the thickness differential increased. Furthermore, the normalized equivalent plastic strain and normalized LDH value were found to be capable of characterizing the influences of varying thickness differentials for a given thickness ratio. This is especially important as these normalized plots demonstrate that while greater thicknesses, represented by an increased thickness differential, may lead to increased structural integrity of a part, no increase in formability is achieved as a result of the increased material.

The results of this research show that increasing the difference of thicknesses in a dissimilar thickness TWB, while maintaining the same thickness ratio, yield roughly the same overall formability as another dissimilar thickness blank of the same thickness ratio. This insight provides valuable guidance for manufacturers that need to adjust thickness to accommodate design changes and other performance allowables.

Author Contributions: Conceptualization, J.W.; methodology, J.W.; software, M.M.; validation, J.W. formal analysis, J.W.; investigation, J.W.; resources, Y.H.; data curation, J.W.; writing-original draft preparation, J.W.; writing-review and editing, Y.H. and M.M; supervision, Y.H. and M.M; project administration, J.W.; funding acquisition, J.W. All authors have read and agreed to the published version of the manuscript.

Funding: This research was funded by Hunan Provincial Education Department, grant number 19A122 and Hunan Institute of Technology, JY201935 and 2019HY025. 
Institutional Review Board Statement: Not applicable.

Informed Consent Statement: Not applicable.

Data Availability Statement: Data supporting the reported results can be obtained from the author upon request.

Acknowledgments: In this section, we acknowledge the support given by Brigham Yong University and Hunan Institute of Technology.

Conflicts of Interest: The authors declare no conflict of interest. The funders had no role in the design of the study; in the collection, analyses, or interpretation of data; in the writing of the manuscript, or in the decision to publish the results.

\section{References}

1. Hovanski, Y.; Upadhyay, P.; Carsley, J.; Luzanski, T.; Carlson, B.; Eisenmenger, M.; Soulami, A.; Marshall, D.; Landino, B.; Hartfield-Wunsch, S. High-Speed Friction-Stir Welding to Enable Aluminum Tailor-Welded Blanks. JOM 2015, 67, $1045-1053$. [CrossRef]

2. Patel, V.; Li, W.; Wang, G.; Wang, F.; Vairis, A.; Niu, P. Friction Stir Welding of Dissimilar Aluminum Alloy Combinations: State-of-the-Art. Metals 2019, 9, 270. [CrossRef]

3. Zhou, Y.; Chen, S.; Wang, J.; Wang, P.; Xia, J. Influences of Pin Shape on a High Rotation Speed Friction Stir Welding Joint of a 6061-T6 Aluminum Alloy Sheet. Metals 2018, 8, 987. [CrossRef]

4. Barbini, A.; Carstensen, J.; Dos Santos, J.F. Influence of Alloys Position, Rolling and Welding Directions on Properties of AA2024/AA7050 Dissimilar Butt Weld Obtained by Friction Stir Welding. Metals 2018, 8, 202. [CrossRef]

5. Wen, Q.; Li, W.Y.; Wang, W.B.; Wang, F.F.; Gao, Y.J.; Patel, V. Experimental and numerical investigations of bonding interface behavior in stationary shoulder friction stir lap welding. J. Mater. Sci. Technol. 2019, 35, 192-200. [CrossRef]

6. Su, Y.; Li, W.; Patel, V.; Vairis, A.; Wang, F. Formability of an AA5083 aluminum alloy T-joint using SSFSW on both corners. Mater. Manuf. Process. 2019, 34, 1737-1744. [CrossRef]

7. Patel, V.; Li, W.; Vairis, A.; Badheka, V. Recent Development in Friction Stir Processing as a Solid-State Grain Refinement Technique: Microstructural Evolution and Property Enhancement. Crit. Rev. Solid State Mater. Sci. 2019, 44, 378-426. [CrossRef]

8. Hovanski, Y.; Carsley, J.; Carlson, B.; Hartfield-Wunsch, S.; Pilli, S. Comparing laser welding technologies with friction stir welding for production of aluminum tailor-welded blanks. SAE Int. J. Mater. Manuf. 2014, 7, 537-544. [CrossRef]

9. Merklein, M.; Johannes, M.; Lechner, M.; Kuppert, A. A review on tailored blanks-Production, applications and evaluation. J. Mater. Process. Technol. 2014, 214, 151-164. [CrossRef]

10. Babu, N.B.K.; Davidson, M.J.; Rao, A.N.; Balasubramanian, K.; Govindaraju, M. Effect of differential heat treatment on the formability of aluminium tailor welded blanks. Mater. Des. 2014, 55, 35-42. [CrossRef]

11. Gautam, V.; Kumar, A. Experimental and Numerical Studies on Formability of Tailor Welded Blanks of High Strength Steel. Procedia Manuf. 2019, 29, 472-480. [CrossRef]

12. Panda, S.K.; Ravi Kumar, D. Experimental and numerical studies on the forming behavior of tailor welded steel sheets in biaxial stretch forming. Mater. Des. 2010, 31, 1365-1383. [CrossRef]

13. Safdarian Korouyeh, R.; Moslemi Naeini, H.; Torkamany, M.J.; Liaghat, G. Experimental and theoretical investigation of thickness ratio effect on the formability of tailor welded blank. Opt. Laser. Technol. 2013, 51, 24-31. [CrossRef]

14. Bhaskar, V.V.; Narayanan, R.G.; Narasimhan, K. Effect of thickness ratio on formability of Tailor Welded Blanks (TWB). AIP Conf. Proc. 2004, 712, 863-868.

15. Safdarian, R. The effects of strength ratio on the forming limit diagram of tailor-welded blanks. Ironmak. Steelmak. 2018, 45, 17-24. [CrossRef]

16. Leitao, C.; Zhang, B.K.; Padmanabhan, R.; Rodrigues, D.M. Influence of weld geometry and mismatch on formability of aluminium tailor welded blanks: Numerical and experimental analysis. Sci. Technol. Weld. Join. 2011, 16, 662-668. [CrossRef]

17. Chien, W.Y.; Pan, J.; Tang, S.C. A combined necking and shear localization analysis for aluminum sheets under biaxial stretching conditions. Int. J. Plast. 2004, 20, 1953-1981. [CrossRef]

18. Song, Y.; Hua, L. Influences of thickness ratio of base sheets on formability of Tailor Welded Blanks. Procedia Eng. 2014, 81, 730-735. [CrossRef]

19. Wang, A.; Liu, J.; Gao, H.; Wang, L.L.; Masen, M. Hot stamping of AA6082 tailor welded blanks: Experiments and knowledgebased cloud-finite element (KBC-FE) simulation. J. Mater. Process. Technol. 2017, 250, 228-238. [CrossRef]

20. Forge NxT, version 2.1; Transvalor: Sophia Antipolis, France, 2018. 